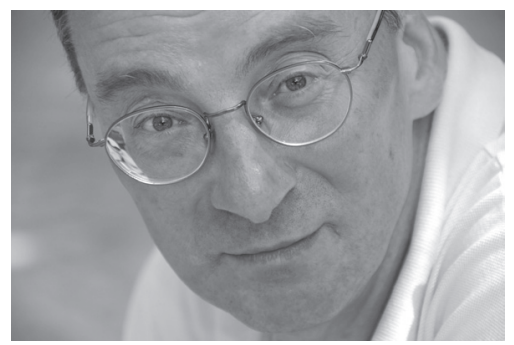

\section{Vor dem nächsten Megatrend}

Die letzten beiden Jahrzehnte in der Sozialwirtschaft waren geprägt von dem Einsatz betriebswirtschaftlicher Methoden in sozialen Unternehmen mit all den politischen, konzeptionellen und fachlichen Folgen, die je nach Standpunkt heftig kritisiert oder freudig begrüßt wurden. Heute braucht sich die Branche vor anderen Wirtschaftszweigen kaum zu verstecken, was Personalmanagement, Prozessoptimierung und Qualitätssicherung angeht. Doch nun scheint auf die Verbände, Einrichtungsträger und Betriebe der Sozialwirtschaft eine neue Innovationswelle zuzurollen, die manche Verantwortlichen möglicherweise noch unterschätzen: Der Einsatz technischer Hilfen in sozialen Dienstleistungen wird sich künftig nicht mehr auf Verwaltungsaufgaben und Kommunikationswege beschränken. Der »Pflegeroboter« ist nur die bekannteste Möglichkeit für den sich abzeichnenden Megatrend. Und auch hier wird der Einsatz technischer Hilfsmittel - wie bei der Betriebswirtschaft - grundlegende Wandlungen mit sich bringen. In vielen Einrichtungen und Diensten, so Helmut Kreidenweis und Bernd Halfar in ihrem Titelbeitrag in diesem Heft, wimmelt es noch nur so von Medienbrüchen, Mehrfacherfassungen, Wissenslücken und Software-Krücken. Gefühlte 10 bis 20 Prozent Effizienzreserven schlummern, so die Vermutung der Autoren, zwischen akribisch abgehefteten Mails, in Word erfassten, ausgedruckten, gefaxten und neu eingegebenen Stammdaten oder selbst gestrickten Excel-Dienstplänen mit kaum mehr durchschaubarem Formeldickicht.

Der Termin für den nächsten Branchentreff steht fest: Der 8. Kongress der Sozialwirtschaft findet vom 12. bis 14. Juni 2013 in Magdeburg statt. Die Themen der Vorträge und Foren werden sich vermutlich um die Sozialwirtschaft als Arbeitsmarkt gruppieren, von der Beschäftigungsentwicklung über die Fachkräfte- und Führungskräftegewinnung bis zu Fragen der Entlohnung. Auch dabei dürften Chancen und Gefahren des immer dominanter werdenden Technikeinsatzes in sozialen Diensten und Einrichtungen eine gewichtige Rolle spielen. Über die aktuelle Veranstaltungsplanung informiert die einschlägige Website des Kongresses der Sozialwirtschaft: www.sozkon.de.

Gerhard Pfannendörfer, Chefredaktion E-Mail pfannendoerfer@nomos.de 